\title{
LA-UR-15-24630
}

Approved for public release; distribution is unlimited.

Title:

Author(s):

Intended for:

Issued:
Automated Powder Dispenser

Kolman, David Gary

Distribution

2015-06-19 
Disclaimer:

Los Alamos National Laboratory, an affirmative action/equal opportunity employer,is operated by the Los Alamos National Security, LLC for the National NuclearSecurity Administration of the U.S. Department of Energy under contract DE-AC52-06NA25396. By approving this article, the publisher recognizes that the U.S. Government retains nonexclusive, royalty-free license to publish or reproduce the published form of this contribution, or to allow others to do so, for U.S. Government purposes. Los Alamos National Laboratory requests that the publisher identify this article as work performed under the auspices of the U.S. Departmentof Energy. Los Alamos National Laboratory strongly supports academic freedom and a researcher's right to publish; as an institution, however, the Laboratory does not endorse the viewpoint of a publication or guarantee its technical correctness. 


\title{
Automated Powder Dispenser
}

\author{
David Kolman \\ Detonator Production
}

June 18, 2015 


\section{Automated Powder Dispenser}

- Historically, powders have been dispensed manually

- Slow (small total masses with high accuracy)

- Tedious

- Ergonomically unfriendly

- Spills

- Manual upload of masses into SOMS

- Variability between operators

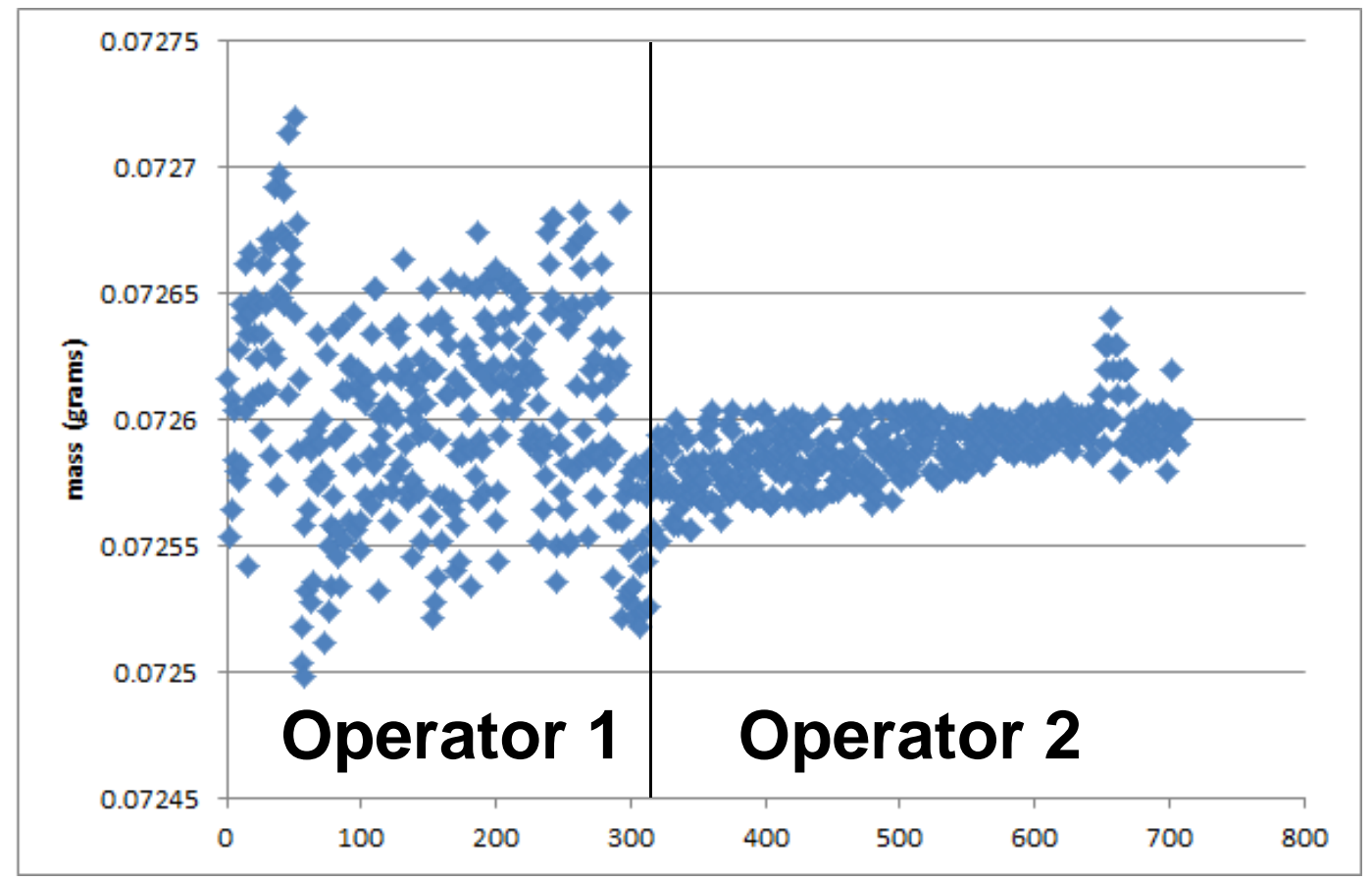




\section{Automated Powder Dispenser}

- Automated powder dispenser improves speed while eliminating ergonomic challenges
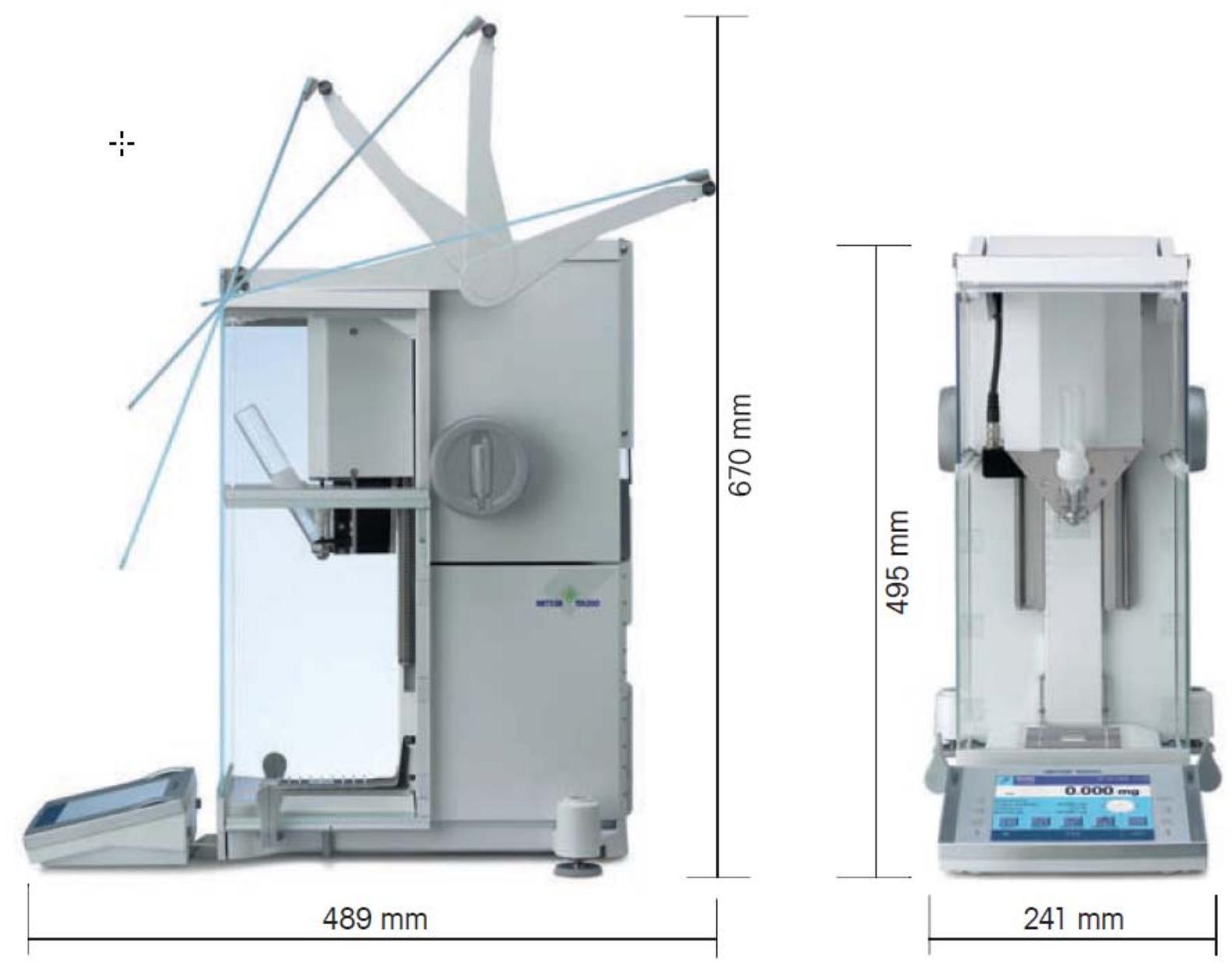


\section{Results}

- Only slight modification of particle size (de-agglomeration rather than crystal break-up?)

- DA has approved use for 1E33 loaded cups

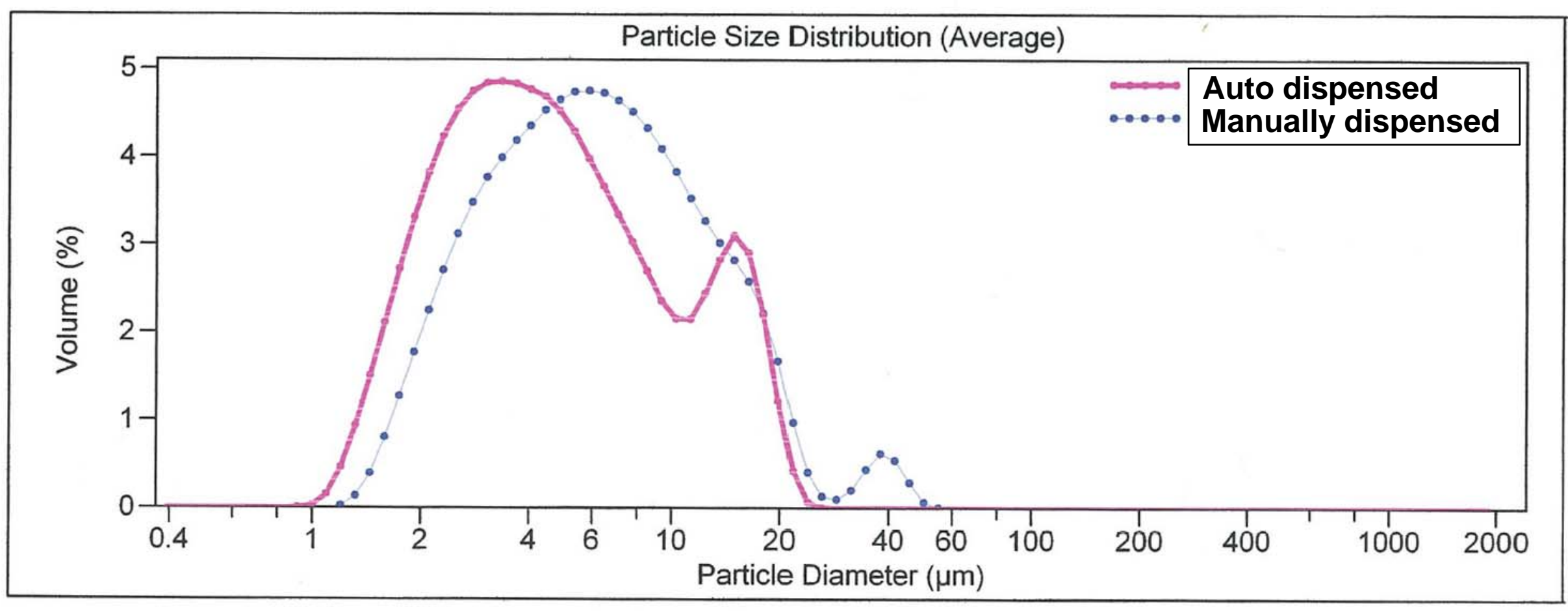




\section{Results}

- Analyzed the $1^{\text {st }}, 2^{\text {nd }}, 5^{\text {th }}, 10^{\text {th }}$ second-to-last and last samples from the dispenser (about 30 samples dispensed). Limited powder segregation between from the first and last dispensing.

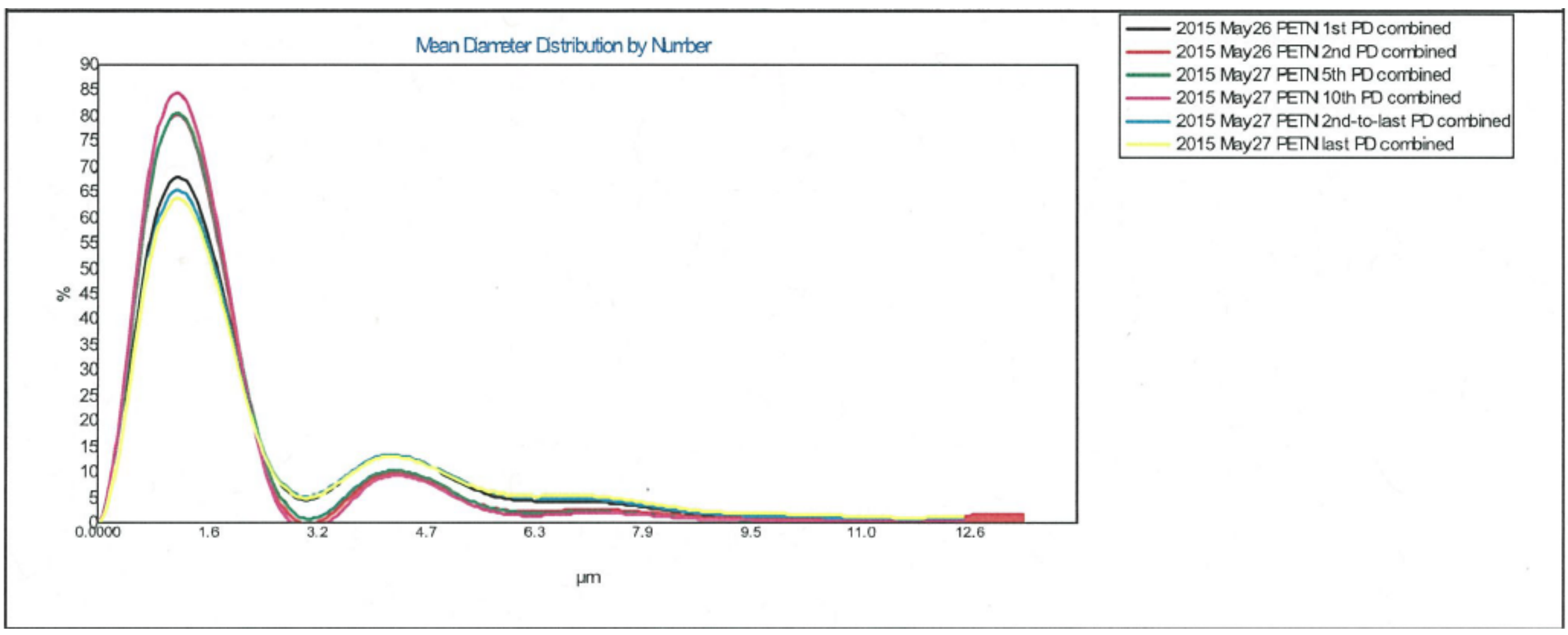




\section{Results}

- DA has approved use for 1E33 loaded cups

- Awaiting approval for IP 